\title{
Uma reflexão sobre a aprendizagem da solubilidade a partir da experimentação
}

A reflection on learning solubility from experimentation

\author{
J. P. L. Gurgel; K. S. Souza* \\ Programa de Pós-Graduação em Ensino de Ciências e Matemática, Universidade Federal do Amazonas (UFAM), \\ 69080-900, Manaus, Amazonas, Brasil \\ *katy_souza@yahoo.com.br
}

(Recebido em 29 de maio de 2020; aceito em 27 de agosto de 2020)

\begin{abstract}
Na perspectiva de um Ensino de Química que incentive a participação, a formulação de argumentos, a associação da Química com o cotidiano e a apropriação do conhecimento por meio de estratégias que se distanciem do habitual, o objetivo foi facilitar a aprendizagem da solubilidade através da experimentação com características investigativas, utilizando os recursos hídricos como temática, valorizando explicações e compreensões associadas aos níveis de representação química. A pesquisa foi realizada com vinte estudantes da primeira série do Ensino Médio de uma escola pública de Manaus, a partir da abordagem qualitativa e enfoque descritivo e exploratório, tendo como instrumentos de coleta de dados, discussões e as atividades experimentais com os dados avaliados a partir da abordagem qualitativa. Os resultados evidenciaram que os estudantes tendem a se expressar apenas utilizando o nível de representação química macroscópico, com dificuldade de transitar entre o macroscópico, submicroscópico e simbólico, e quando empregadas estratégias de ensino-aprendizagem não comuns ao dia-dia escolar, em que sejam necessárias mobilizações do conhecimento, estes apresentam dificuldades em relacionar o científico ao contexto. Em relação a temática recursos hídricos, ainda há um longo caminho de sensibilização ambiental a ser realizado porque a maioria se abstém ou responsabiliza outros pelas ações referentes ao meio ambiente.

Palavras-chave: Ensino de Química, Solubilidade, Experimentação.
\end{abstract}

In the perspective of a Chemistry Teaching that encourages participation, the formulation of arguments, connect to Chemistry with everyday situations and the appropriation of knowledge through strategies that distance themselves from the usual, the objective was to facilitate the learning of solubility through experimentation with investigative characteristics, used water resources as the theme, valuing explanations and understandings associated with the levels of chemical representation. The research was performed with twenty students from the first grade of high school at a public school in Manaus, using a qualitative approach and a descriptive and exploratory emphasis, using data collection instruments, discussions and experimental activities with the data evaluated from the qualitative approach. The results showed that students tend to express themselves only using the level of macroscopic chemical representation, with difficulty in transitioning between the macroscopic, submicroscopic and symbolic, and when teachinglearning strategies that are not common in the school day are used, necessary mobilizations of knowledge, they present difficulties in relating the scientific to the context. Regarding the theme of water resources, there is still a long way to go to raise environmental awareness because the majority abstain or hold others responsible for actions related to the environment.

Keywords: Teaching of Chemistry, Solubility, Experimentation.

\section{INTRODUÇÃO}

A Química é uma ciência central, presente no cotidiano e no progresso da sociedade, que tem nas dificuldades de aprendizagens, como cálculos matemáticos, abstração (em nível submicroscópico), linguagem científica, memorização de fórmulas, fragmentação do conteúdo, distanciamento do dia-a-dia, entre outras, fatores que a tornam uma disciplina escolar considerada difícil, diminuindo o interesse pela mesma [1, 2, 3]. A abstração, apontada como um dos principais entraves para o processo de ensino-aprendizagem da Química, devido ao uso de conceitos que não estão palpáveis a realidade dos alunos, principalmente conceitos atomísticos e moleculares representados apenas por modelos [4], é potencializada por metodologias que não favorecem a aprendizagem e não associam a Química ao cotidiano. 
Wharta e Resende (2017) [5] apontam Johnstone como um dos primeiros a propor a existência de três níveis de representação química, o nível macroscópico, submicroscópico e o simbólico, e a dificuldade dos alunos em utilizar ou expressar sua aprendizagem nos três níveis de representação, sendo mais comum à utilização do nível macroscópico para explicar fenômenos químicos, devido, geralmente o aprendizado ocorrer apenas neste nível, com os demais níveis exigindo maior capacidade de abstração.

Nesse sentido, a experimentação é interessante como estratégia de ensino, por minimizar esses entraves, pois além de contribuir com a aprendizagem de conceitos químicos nos universos macroscópico, submicroscópico e simbólico pode envolver valores e atitudes em uma educação cidadã, cujo indivíduo é preparado para agir de forma mais crítica $[6,7]$ como preconizam os documentos oficiais da Educação. A experimentação como estratégia de ensino-aprendizagem promove a interação social, o trabalho em equipe, desenvolve a habilidade de observar e medir, a construção de conceitos, trabalha as atitudes, aumenta o interesse pela Ciência, é motivadora e lúdica, entre outros $[8,9,10]$.

Existem diversas classificações para as atividades experimentais e, para Araújo e Abib (2003) [11], as abordagens experimentais podem ser de: demonstração onde a participação do aluno é de observação, cabendo ao professor a execução do experimento, verificação que tem a finalidade de comprovar e verificar uma lei, cujos resultados são conhecidos dos alunos e investigação que permitem ao aluno uma participação mais ativa no processo de aprendizagem, cabendo ao professor a mediação.

Na abordagem experimental investigativa não há uma dependência prévia dos conteúdos, estes podem ser desenvolvidos no decorrer e contexto da atividade, os resultados não são previsíveis e os alunos participam de forma mais ativa, buscando explicações e fazendo interpretações auxiliados pelo professor que atua incentivando e questionando [12].

De acordo com Menezes e Farias (2020) [13] a experimentação investigativa envolve, obrigatoriamente, etapas como a "discussão de ideias a partir de situações problema, elaboração de hipóteses explicativas e ações para testá-las, e análise e comunicação dos resultados". Estimulando "a interatividade intelectual, física e social, contribuindo de forma intensa na construção de conceitos". Borges (2002) [6] sugere que essas atividades experimentais investigativas sejam desenvolvidas inicialmente de modo simples, levando em conta "a experiência com atividades do mesmo tipo", e o conhecimento dos alunos em relação ao tópico investigado, podendo-se utilizar materiais de apoio que auxiliem os alunos, permitindo que esses assumam o controle das atividades progressivamente.

Segundo Giordan (1999) [10]:

"A elaboração do conhecimento científico apresenta-se dependente de uma abordagem experimental, não tanto pelos temas de seu objeto de estudo, os fenômenos naturais, mas fundamentalmente porque a organização desse conhecimento ocorre preferencialmente nos entremeios da investigação. Tomar a experimentação como parte de um processo pleno de investigação é uma necessidade, reconhecida entre aqueles que pensam e fazem o ensino de ciências, pois a formação do pensamento e das atitudes do sujeito deve se dar preferencialmente nos entremeios de atividades investigativas" [10, p.44].

Entendendo que a articulação entre os saberes cotidianos e científicos pode facilitar a aprendizagem e buscando trabalhar numa vertente diferente da abstração promovida pelos conceitos atomísticos e moleculares, o conceito de solubilidade é mais palpável aos alunos, pois o cotidiano os expõe a situações diárias, onde é possível perceber substâncias se solubilizando, como: a manicura que limpa o esmalte das unhas das clientes nos salões, o pintor que utiliza a querosene ao término do seu serviço, quando se usa sabão ou detergente na limpeza de gordura das louças, entre outras [14].

Para Carmo e Marcondes (2008) [15] compreender o conceito de solubilidade cientificamente "exige que o aluno reorganize suas concepções", para que o nível de representação cognitiva consiga evoluir do menos complexo para mais complexo. Nesse caso a interação entre professor 
e aluno serve como articulação para que a reorganização ocorra através de reflexões e não apenas como uma mudança de concepção.

É importante que o Ensino de Química mobilize os aspectos conceituais buscando a ampliação do desenvolvimento cognitivo do aluno, abrangendo os três níveis de representação química, mas também desenvolva atitudes a partir de contextos reais aproximando a química da vida de maneira significativa.

\footnotetext{
"Não se procura uma ligação artificial entre conhecimento científico e cotidiano, restringindo-se a exemplos apresentados como ilustração ao final de algum conteúdo; ao contrário o que se propõe é partir de situações problemáticas reias e buscar o conhecimento necessário para entendê-las e procurar solucioná-las" [16, p. 5].
}

Assim, o presente trabalho utilizou a experimentação, para associar os níveis de representação química, o cotidiano e a aprendizagem da solubilidade, a partir de atividades que ressaltaram as representações formuladas pelos estudantes e a forma como os mesmos conseguem relacionar aquilo que veem ou imaginam com os conceitos científicos no processo de ensino-aprendizagem.

O objetivo foi desenvolver a temática poluição dos recursos hídricos, relevante no contexto amazônico juntamente com a experimentação com características investigativas para facilitar a aprendizagem da solubilidade, valorizando explicações e compreensões associadas aos níveis de representação química [17].

\section{MATERIAL E MÉTODOS}

A pesquisa pautou-se na abordagem qualitativa, por envolver temas sensíveis ou situações em que o universo da pesquisa é pequeno [18], considerando a interpretação pessoal, motivações e emoções de cada indivíduo pertencente ao contexto pesquisado. O caráter descritivo e exploratório buscou construir hipóteses, ampliar reflexões e proporcionar maior familiaridade com as situações propostas [19].

Participaram da pesquisa 20 alunos, do primeiro ano do Ensino Médio regular de uma escola pública de Manaus, do turno vespertino, e as atividades ocorreram no sexto tempo de aula criado para esse fim. A pesquisa foi aprovada pelo Comitê de Ética em Pesquisa - CEP - UFAM, sob o parecer 2.311.809, para garantir aos envolvidos, os direitos pertinentes à legalidade de uma pesquisa com fins educacionais e resguardar o anonimato dos alunos participantes, identificados de forma alfanumérica, exemplo A10.

Os dados foram coletados por meio da sequência didática apresentada no Tabela 1, utilizando atividades experimentais com características investigativas, dentre elas, questionamentos iniciais e o levantamento de hipóteses [6] desenvolvendo a temática poluição dos recursos hídricos a partir do uso de detergentes líquidos e sabões, aproximando o conceito químico de solubilidade com o cotidiano dos alunos, uma vez que a escola está localizada dentro de um campus universitário onde passa um igarapé poluído, sendo o tema relevante na sociedade amazonense, considerando a abundância de recursos hídricos no Estado do Amazonas.

Cabe ressaltar que a temática, guiou os experimentos, levantamento de hipóteses e explicações. E os experimentos foram pensados no sentido de despertar o senso de investigação e criticidade, com pequeno custo, seguros para a realização, visualmente claros quanto à observação dos fenômenos e a possibilidade de explorar os níveis de representação química [22]. Os dados foram interpretados e discutidos, a partir das observações e argumentações dos estudantes, com abordagem qualitativa. 
Tabela 1: Sequência aplicada na coleta de dados.

\begin{tabular}{|c|c|}
\hline Encontros & Atividades \\
\hline Encontro 1 (2h) & $\begin{array}{l}\text { Abordagem geral, retratando a poluição dos recursos hídricos e uma } \\
\text { contextualização local, com a leitura de uma reportagem relacionada à } \\
\text { poluição de um famoso igarapé da cidade de Manaus. }\end{array}$ \\
\hline Encontro $2(2 \mathrm{~h})$ & $\begin{array}{l}\text { Após interpretação e discussão inicial dos problemas: O que você acha que } \\
\text { acontece com a espuma do detergente que vai para o ralo depois que você } \\
\text { lava a louça? Por que é necessário usar detergentes e como eles atuam? } \\
\text { Será que causam poluição dos recursos hídricos? Solicitou-se a } \\
\text { formulação de hipóteses de como determinar a solubilidade das } \\
\text { substâncias, a partir da interação da água com os sabões e a necessidade } \\
\text { de produtos de limpeza para remoção de sujeiras, seguindo-se de } \\
\text { discussões conceituais acerca da polaridade e solubilidade das substâncias. }\end{array}$ \\
\hline Encontro 3 (2h) & $\begin{array}{l}\text { Foram propostas pelo pesquisador três situações experimentais, que os } \\
\text { estudantes desenvolveram e formularam explicações, com base em seus } \\
\text { conhecimentos cotidianos, científicos e observacionais, o texto [20] foi } \\
\text { utilizado como apoio para as explicações e interpretações. } \\
\text { No experimento } 01 \text { os alunos adicionaram leite em um recipiente para } \\
\text { formar uma película na superfície, em seguida adicionaram gotas de } \\
\text { corantes e depois gotas de detergentes, para mostrar o efeito das diferenças } \\
\text { de polaridade e o efeito do detergente no processo de misturar as } \\
\text { substâncias através de sua estrutura diferenciada [21]. } \\
\text { Experimento } 02 \text { em três tubos de ensaio adicionou-se água, e } \\
\text { respectivamente: óleo de cozinha, gasolina e álcool. Pediu-se aos alunos } \\
\text { que tentassem misturar, observar e realizar anotações. Em seguida os } \\
\text { alunos foram orientados a adicionar gostas de detergente em cada tubo, } \\
\text { mexer, observar, registrar os resultados e discutir quimicamente a ação do } \\
\text { detergente em cada mistura [21]. } \\
\text { No experimento } 03 \text { os alunos foram orientados a colocar em uma proveta } \\
\text { uma quantidade de glucose de milho; em seguida adicionar água com } \\
\text { corante verde, depois adicionar óleo de cozinha com corante azul, } \\
\text { adicionar álcool com corante vermelho, adicionar com cuidado querosene } \\
\text { com corante amarelo, mexendo e observando a cada adição na proveta } \\
\text { [21]. Esse experimento foi realizado com o intuito de mostrar a ausência } \\
\text { de interação entre as substâncias. }\end{array}$ \\
\hline Encontro 4 (2h) & $\begin{array}{l}\text { Debate sobre a poluição dos recursos hídricos e o uso de detergentes ou } \\
\text { sabões, pois estes foram tratados durante a sequência como uma das fontes } \\
\text { de poluição. }\end{array}$ \\
\hline
\end{tabular}

\section{RESULTADOS E DISCUSSÃO}

\subsection{Hipóteses para Determinar a Solubilidade das Substâncias}

A atividade despertou grande interesse nos alunos em participar e foi pensada no sentido de promover o senso investigativo dos participantes, trabalhando a temática e instigando-os a formular hipóteses sobre como determinar a solubilidade das substâncias.

Nas primeiras discussões, relacionadas aos questionamentos iniciais do encontro 2 , observouse o empenho de todos para entender o que seria a solubilidade e apropriar-se do conceito para propor as hipóteses. Para Oliveira et al. (2009) [14] "apropriar-se do conhecimento é pensar sobre as situações do mundo, usando-o para entendê-las. No caso da Química trata-se de ser capaz de pensar sobre o mundo material utilizando os conhecimentos químicos". 
Considerando a forma como os participantes conseguiram identificar e refletir a solubilidade, e utilizando palavras e proposições por eles usadas, quatro categorias foram criadas, buscando interpretar as considerações dos participantes (Tabela 1).

Tabela 1: Determinando a solubilidade das substâncias.

\begin{tabular}{ccc}
\hline Questionamento & Categorias & Unidades de Análise \\
\hline \multicolumn{1}{c}{$\begin{array}{c}\text { Como determinar a } \\
\text { solubilidade das } \\
\text { substâncias? }\end{array}$} & Macroscópica & $\mathrm{A} 16, \mathrm{~A} 17, \mathrm{~A} 02, \mathrm{~A} 12, \mathrm{~A} 03 \mathrm{e}$ \\
& Transitória & $\mathrm{A} 20, \mathrm{~A} 08, \mathrm{e}$ A14, A01 \\
& Submicroscópica & $\mathrm{A} 18, \mathrm{~A} 04, \mathrm{~A} 06, \mathrm{~A} 07, \mathrm{~A} 11 \mathrm{e}$ \\
& A13 \\
& Relações confusas & $\mathrm{A} 09, \mathrm{~A} 10, \mathrm{~A} 15$ e A19 \\
\hline Legenda: A+ número é identificação dos estudantes. Fonte: os autores.
\end{tabular}

Seis alunos utilizaram características macroscópicas como meio para determinar a solubilidade, explicando que se a substância a ser solubilizada é "gordurosa" não ocorrerá solubilidade. Ao utilizar essa explicação os alunos deixam de considerar que existem substâncias insolúveis em água que não são gordurosas.

“Quanto mais à substância é gordurosa menos ela é solúvel” (A17).

Outro grupo de alunos que também considerou apenas as características macroscópicas, sugeriu que sejam feitos testes para identificar a polaridade, pois se sabe que "semelhante dissolve semelhante", nesse caso identificar-se-iam as substâncias solúveis em água como polares através de experimentos.

"Colocando a substância na água, caso a substância interaja com a água ela é polar, caso não interaja ela é apolar” (A12).

Apesar de levarem em conta o conceito científico da polaridade, identifica-se certa superficialidade na argumentação, e questiona-se a que semelhança se referem em sua resposta? Pois, se pensassem em termos de ligações químicas, compostos iônicos como $\mathrm{NaCl}$ se dissolvem em água cujas ligações são predominantemente covalentes [14].

Wartha e Rezende (2011) [17] discorrem que o nível macroscópico de representação corresponde ao concreto, ou seja, aquilo que está palpável ao observador, nesse caso o nível de abstração é menor e assim é mais fácil para o aluno explicar nestes termos suas interpretações. Foi o que os alunos fizeram, usaram a forma mais simples para explicar apenas através do observável. Não se pode desconsiderar esse nível de representação ou mesmo a forma simplificada de explicar os fenômenos, pois a interação entre esses saberes servirá de base para a construção de novos conhecimentos.

Corrobora-se com o entendimento de que os níveis de representação química são como vértices de um triângulo, e em cada lado, um conhecimento, nesse caso macroscópico, submicroscópico e simbólico, mobilizar de maneira equivalente esse conhecimento, percorrendo os três vértices, possibilitaria ao aluno a capacidade de desenvolver a abstração e a habilidade de modelagem [5, 17]. Contudo, esse processo não é fácil, pois, seria necessário desenvolver habilidades em estudantes que estão acostumados a tomar o direcionamento mais fácil.

Vale ressaltar que insistir na ausência ou pouca discussão acerca de como os conceitos se constroem e relacionam com o cotidiano, no processo de ensino-aprendizagem, valoriza a memorização e a ausência de compreensão dos mesmos [7]. Logo, é fundamental o estímulo por meio de atividades que busquem desenvolver a argumentação e a reflexão de forma gradual.

Alguns alunos, nessa etapa de proposição de hipóteses para determinar a solubilidade, a exemplo do A20, conseguem utilizar as características submicroscópicas na proposição de investigações, através de modelos teóricos, explicativos, descritivos do comportamento das 
moléculas (representacional), ou seja, sua percepção é transitória nos níveis de conhecimento químico.

"Analisar primeiro a estrutura molecular da substância;

Identificar pela estrutura o seu comportamento em termos de polaridade;

Depois observar o fenômeno através de experimento" (A20).

A análise da estrutura molecular sugere escrever a fórmula, assim além da visão submicroscópica, o estudante também utilizou a representação simbólica, e ao sugerir observar o experimento, partiu para a visão macroscópica do fenômeno.

"A polaridade se determina quando vemos a sua estrutura molecular e de acordo com o texto quando interage com a água. A solubilidade pode ser identificada quando ela é misturada à outra substância, na maioria das vezes a água" (A20).

Observa-se que o estudante considerou que se for colocada em meio aquoso, uma substância polar deve solubilizar-se, e se a substância é apolar não será solubilizada, assim utilizou a visão macroscópica para complementar sua explicação. Essa resposta mostra uma importante vertente da experimentação, em que o aluno ao utilizar a prática associada aos conceitos, transita pelos diferentes níveis de representação nos quais a ciência deve ser trabalhada para tecer suas considerações.

Por meio de modelos e teorias, alguns alunos também levantaram hipóteses/sugestões para a determinação da solubilidade das substâncias, através da eletronegatividade, polaridade, características submicroscópicas, ou mesmo pela densidade, sugerindo ser possível saber se as substâncias são solúveis em água ou não.

"Podemos identificar pela eletronegatividade, que em substâncias polares é grande e não permite que se misture com moléculas apolares que não tem diferença de eletronegatividade" (A06).

O lado dos aspectos mais estruturais correspondentes ao vértice do submicroscópico contribui na capacidade de modelagem. A compreensão das transformações químicas num nível que requer uma maior capacidade de abstração como é o caso do nível submicroscópico é muito importante no Ensino de Química, visto que é uma ciência construída com base experimental que exige muita abstração. Wartha e Rezende (2011) [17] defendem a ideia de que no processo de ensino e aprendizagem em Química o nível submicroscópico é o mais importante e junto com o simbólico constituem a base para a significação do nível macroscópico. É necessário enfatizar que muitas vezes as dificuldades em relação ao submicroscópico são pela falta de sua exercitação, no entendimento de que as manipulações mentais são muito complexas, cria-se no estudante a falsa ideia que "a memória é mais importante que a imaginação, sendo o conhecimento um privilégio dos que tem mais tempo para exercitá-la" [2].

Azzolin (2012) [23] ao estudar as concepções dos estudantes sobre solubilidade observou que é comum, estudantes da primeira série do Ensino Médio apresentarem ideias conceituais errôneas ou confusas, assim como apresentarem dificuldades em explicar as interações entre as partículas de soluto e solvente. Nesta pesquisa observou-se que alguns alunos não conseguem diferenciar substâncias de elementos químicos, exemplo:

\footnotetext{
"fazendo análises, experimentos, com o elemento desejado" (A19).

"quando a substância tem aversão pela água, pois o hidrogênio é diferente do oxigênio. Assim determina a polaridade e solubilidade" (A09)
}

Para tentar explicar essas relações confusas parte-se da hipótese, que de modo geral, podem ser resultado de um ensino fragmentado e descontextualizado, que não estabeleceu relações entre os conteúdos de formação dos conceitos [24], ou das dificuldades de aprendizagem individuais, mostrando que é preciso um trabalho cuidadoso, explorando com os alunos as diferenças e 
hierarquias conceituais, possibilitando a assimilação do macroscópico, submicroscópico e simbólico, para que essas relações sejam desenvolvidas a ponto de construírem conhecimentos sem que haja confusão na interpretação e aprendizado dos conceitos.

$\mathrm{Na}$ segunda etapa, de atividades experimentais, os participantes, supervisionados, realizaram três experimentos, que mostram o efeito do detergente na solubilidade de algumas substâncias.

\subsection{Discussões do Experimento 01}

Ao gotejar corante em um recipiente com leite e em seguida acrescentar algumas gotas de detergente líquido, é possível observar e analisar a interação entre essas substâncias (Figura 1).

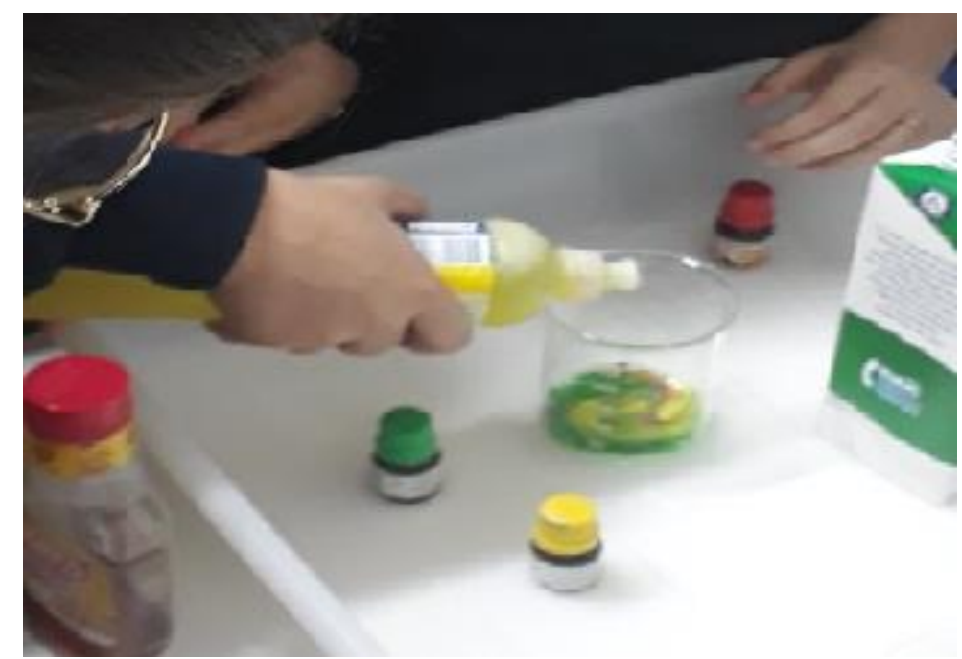

Figura 1: Realização do Experimento 01. Fonte: os autores.

A explicação para o experimento é que ao gotejar corante no leite os dois não misturam, pois, o leite possui uma camada de gordura na superfície que por ser apolar não consegue interagir com as moléculas do corante e cada cor fica separada, mas ao pingar detergente na mistura ocorre uma quebra da tensão superficial do leite, pois a cadeia longa do detergente interage com a gordura do leite e sua parte polar interage com o corante proporcionando a mistura.

Lembrando que o conceito de solubilidade foi sendo abordado no decorrer da sequência didática para auxiliar nas construções e argumentações individuais, os estudantes foram questionados sobre a explicação para o fato de o corante e o leite não se misturarem, e direcionaram suas explicações para dois conceitos químicos: densidade e polaridade. Alguns utilizaram os dois conceitos para explicar a não solubilização das sustâncias e outros explicaram somente com um dos conceitos, ou densidade ou polaridade.

A maioria usou o conceito de densidade na explicação, se utilizando apenas do visual, ou seja, macroscópico, não levando em consideração as possíveis interações em nível submicroscópico, aceitável pelo efeito visual do fenômeno. Alguns responderam de forma confusa o que é compreensivo considerando que os estudantes não estão acostumados com esse tipo de atividade, e suas habilidades observacionais estão em desenvolvimento, além disso, na expectativa e inquietação para realizar a atividade, são precipitados nas respostas, pouco discutindo entre si ou com o professor as possibilidades científicas para a interpretação.

Atividades dessa natureza devem ser desenvolvidas com frequência devido a possibilidade de desenvolver saberes conceituais, procedimentais e atitudinais, além de permitir ao professor corrigir erros conceituais durante o desenvolvimento.

Ainda no experimento 01 verificou-se de que forma os alunos conseguiam identificar o efeito químico do detergente sobre o corante no leite e explicar por que esse efeito ocorreu. Algumas respostas foram:

"ele diminui a interação entre as moléculas, esse efeito acontece porque ele diminui a tensão superficial” (A17).

"ele dissolveu, pois o corante é polar" (A14, A12, A11). 


\begin{abstract}
"o leite é gorduroso (apolar) e o corante é solúvel em água (polar)" (A17). "pois o leite é composto de gordura então ele é apolar, e o corante tem água na sua composição que é polar, e a gordura não se mistura com a água, pois não são semelhantes então eles não dissolvem"(A01).
\end{abstract}

Nas respostas é possível evidenciar a mobilização do nível submicroscópico quando se levam em consideração interações que não são percebidas a olho nu, e essa transição entre os níveis auxilia no processo aprendizagem, favorecendo construções mentais, superando o entrave da abstração. De acordo com Gatti et al. (2015) [25] nas observações macroscópicas estimula-se explicações submicroscópicas. No entanto, mesmo usando a polaridade e tensão superficial nas explicações, não é percebida apropriação do conceito de solubilidade, mas já ocorre uma reorganização conceitual em relação às primeiras hipóteses auxiliada pela experimentação.

Por outro lado, alguns alunos fizeram associação da ação do detergente misturado ao corante e leite, com a repulsão entre cargas iguais, descrita pela Lei Física da eletricidade, o que não é o caso uma vez que o fenômeno ocorrido é o de interação entre moléculas que atuam sim através de cargas, mas cargas opostas. Portanto, os alunos que fizeram esta associação utilizaram do fenômeno físico que não é o caso neste experimento.

“Eles se repelem, eles tem polos iguais se repelem” (A03, A07).

Também houve alunos, cuja explicação foi uma descrição empírica, sem discussões conceituais, que embora distantes da visão científica, são base para o aprendizado, uma vez que trabalham a observação no nível macroscópico.

“ele faz a mistura entre o leite e o corante” (A16).

Schnetzler (2002) [26] afirma que não se deve descartar o conhecimento de senso comum e sim aproveitar e provocar um diálogo entre ele e o conhecimento científico, que geralmente não faz parte do meio cultural dos alunos, sendo necessária uma valorização dessas ideias para que o conhecimento científico possa fazer sentido e tornar-se importante para o aprendizado.

\title{
3.3 Discussões do Experimento 02
}

Ao misturarem nos tubos de ensaio substâncias com polaridades diferentes e posteriormente adicionarem o detergente, novamente os alunos tiveram a oportunidade de observar as diferenças e a interação do detergente com as misturas (Figura 2).

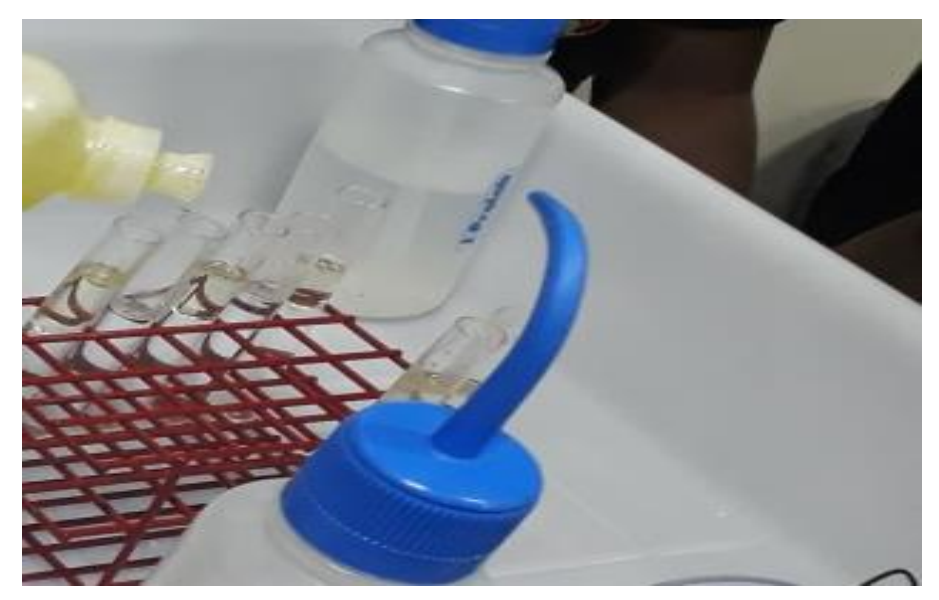

Figura 2: Realização do Experimento 02. Fonte: os autores.

Esperava-se que as respostas explanassem que o detergente tem em sua estrutura molecular uma parte polar e outra apolar, que possibilita a interação com substâncias de polaridades diferentes. 
Como resultado, oito alunos explicaram utilizando o conceito de polaridade e sete consideraram a densidade responsável pelas substâncias não se misturarem com a água. O A17 associou à solubilidade a diferença entre as substâncias, porém não explicou a quais diferenças se referia.

“não podem se misturar por serem diferentes" (A17).

Os alunos A04, A09, A18 e A19 falaram sobre a mistura ser heterogênea e de forma bem simplificada disseram que isso impede as substâncias interagirem, claramente associando a solubilidade apenas ao macroscópico.

\footnotetext{
“são heterogêneos, não se misturam” (A04).

"a mistura é heterogênea então não conseguem se juntar” (A18).
}

A problematização com base na solubilidade das misturas configurou-se como uma estratégia importante para a reflexão sobre as interações da água com as substâncias utilizadas no experimento. As discussões sobre homogeneidade, heterogeneidade, regras de solubilidade, polaridade e densidade permitiram que os alunos saíssem do método tradicional de ensino, trabalhando o visualizar, julgar, levantar hipóteses, argumentar e propor explicações, estimulando uma discussão no sentido de compreender a forma como as sustâncias interagem e consequentemente os conceitos de solubilidade e polaridade em associação com a poluição cotidiana dos recursos hídricos.

Melo e Silva (2019) [7] ressaltam que para vencer dificuldades de aprendizagem, muitas vezes é necessário "iniciar a abordagem a partir do macro (tangível) que é familiar aos estudantes e gradualmente enriquecê-la com os níveis molecular e invisível, simbólico e matemático".

O desenvolvimento do pensamento crítico que permeia a aprendizagem conceitual relacionada com aspectos de natureza social, política e econômica, é fundamental na realização de experimentos, por isso, é importante a discussão dos conceitos químicos associados a temáticas, para que os alunos possam compreender não só os conceitos, mas, também suas aplicações [27].

Ao trabalhar conceitos em sala de aula é necessário enfatizar que a Ciência é uma construção humana, passível de mudanças, e a experimentação proporciona a familiarização com o processo científico e pode promover uma nova percepção do fazer ciência [28].

\subsection{Discussões do experimento 03}

Numa proveta foram adicionadas várias substâncias, com o objetivo de mostrar a falta de interação entre substâncias com polaridades diferentes (Figura 3).

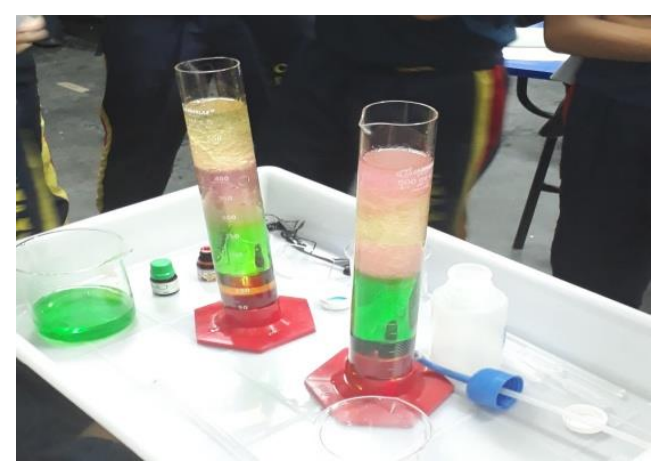

Figura 3: Realização do Experimento 03. Fonte: os autores.

Das respostas, treze alunos falaram que os líquidos não se misturam devido às densidades serem diferentes, a seguir algumas respostas onde utilizaram o conceito de densidade:

“eles têm densidades e polaridades diferentes" (A03). 
"não se misturam, pois os produtos usados no experimento possuíam densidades diferentes" (A05).

"Temos que ver que o óleo e o mel são hidrofóbicos, o mel é mais pesado, denso e também é pela densidade que é diferente"(A06).

Quatro disseram que as densidades e as polaridades diferentes impedem que os líquidos se misturem, um falou somente sobre a polaridade das moléculas e dois alunos responderam de forma confusa.

\footnotetext{
“ não se misturaram pela diferença de densidade e polaridade” (A01 e A04).

"Não misturam por não serem semelhantes as polaridades" (A02).
}

Os alunos não explicaram a relação massa por volume que corresponde à densidade, o que mostra uma associação muito superficial e talvez até equivocada, ao utilizar somente o conceito de massa, ao afirmar que os de baixo são mais pesados. Segundo Borges (2017) [29] é comum à associação de massa com densidade e considerar que aquilo que afunda tem massa maior, nesse caso como o mel fica embaixo, o aluno fala da densidade maior e considera que é o mais denso.

Para Titoni e Del Pino (2008) [30] comumente os alunos não têm conceitos suficientemente elaborados a respeito da polaridade associada à solubilidade das substâncias. Porém, observou-se que metade dos alunos se referem à polaridade como motivo para não solubilidade das substâncias nos três experimentos.

\begin{abstract}
"Solubilidade, por definição, é a concentração de soluto dissolvido em um solvente em equilíbrio com o soluto não dissolvido à temperatura e pressão especificadas, ou seja, é a medida da quantidade máxima de soluto que pode ser dissolvida em um determinado solvente. O tamanho molecular (ou iônico), a polaridade (ou carga), forças dispersivas e dipolares, ligações de hidrogênio e a temperatura são fatores que se destacam na determinação da solubilidade e devem ser considerados no seu entendimento" [31, p.1016].
\end{abstract}

O participante A04 explicou: "não se misturam porque algumas misturas são heterogêneas". O conceito de mistura heterogênea é um dos primeiros conceitos trabalhados no Ensino Médio, portanto é bem comum os alunos caracterizarem as misturas que não se solubilizam como misturas heterogêneas, essas não apresentam aspectos semelhantes em toda sua extensão, assim embora o aluno A14 não tenha utilizado o conceito de polaridade para explicar o fato de as substâncias não se misturarem, este aluno utilizou-se de aspectos macroscópicos para explicar a questão.

Para Gatti et al. (2015) [25] é preciso ultrapassar o aspecto macroscópico presente nos experimentos, uma vez que experimentos constituem-se de atividades nas quais os fenômenos são observáveis a olho nu, é preciso que os alunos possam observar também em termos de modelos pois assim a experimentação possibilitará a discussão de conteúdos nos diferentes níveis de representação, embora a importância do nível macroscópico seja grande não é o suficiente para a compreensão dos aspectos que envolvem o fenômeno.

Diante dos resultados, concorda-se que atividades dialogadas, pautadas no cotidiano, com caráter colaborativo e participativo, auxiliam no processo de ensino-aprendizagem ao considerar conteúdos, questões sociais e as ideias dos estudantes [14]. Entretanto, esse processo de desenvolvimento argumentativo e reflexivo a partir de atividades experimentais demanda tempo, sendo importante iniciar com atividades simples [6].

\title{
3.5 Debate sobre a poluição dos recursos hídricos e o uso de detergentes ou sabões
}

Ao final dos experimentos ocorreu um debate com intuito de associar o uso dos detergentes, com os conceitos científicos solubilidade e polaridade e a poluição dos recursos hídricos.

Para que a interação com o meio seja consciente é preciso saber sobre os processos de fabricação e as implicações ambientais do uso de sabões e detergentes para o planeta, em especial para os recursos hídricos, pois para "um julgamento adequado, é necessária a aquisição de informações, conhecimento das leis para os atos corriqueiros da vida" [32]. 
Explicou-se que a produção de sabão necessita de um óleo ou gordura para reagir com uma base, como as gorduras são cadeias de ácidos orgânicos ocorre quimicamente à reação de ácido e base que consequentemente produz sal e todo sal tem caráter iônico em pelo menos uma ligação, assim os sabões têm em suas cadeias essa região de caráter iônico que produz uma polarização e sua atuação se dá na tensão superficial dos líquidos, no sentido de diminuir a coesão, portanto, um redutor de tensão superficial, o que pode promover a solubilização de substâncias na água [33].

O não tratamento das águas residuais, dos esgotos domésticos levam os sabões para os rios e a água contendo sujeira e sabão podem tornar se alimentos para microrganismos que irão se proliferar e causar a eutrofização das águas com a produção de metano, amônia e ácido sulfídrico por parte dos microrganismos prejudicando assim o meio ambiente. Com isso, os alunos foram incentivados refletir sobre meios para higienizar as louças sem agredir o meio ambiente, principalmente os recursos hídricos.

Das propostas, seis alunos apontaram a substituição de detergentes normais por biodegradáveis ou sabões normais ou de coco, dois sugeriram a utilização de álcool no lugar de detergentes, o que evidencia evolução em relação ao debate inicial da sequência didática, onde não houve nenhum comentário no sentido da utilização de produtos menos agressivos, ou biodegradáveis. Oito alunos não responderam e dois disseram que não existem formas de limpar as louças sem poluir o meio ambiente, dois alunos acham que existem, mas não sabem quais os meios.

É importante considerar neste resultado, que $60 \%$ dos estudantes, têm dificuldade em assumir ou trazer para si a responsabilidade social abordada nas discussões, seja por omissão, desistência ou falta de informação e mostra a necessidade de abordagens que estimulem o debate das obrigações de cada cidadão com o meio ambiente e sociedade. Ressalta-se que a sequência foi desenvolvida no intuito de associar o conceito de solubilidade a poluição dos recursos hídricos, e tornar perceptível no decorrer das atividades que o uso de detergentes e sabões facilita a solubilização de poluentes nas águas, buscando o julgamento a partir do conhecimento científico trabalhado.

Apesar dos esforços contextuais, a falta de compromisso ambiental ficou mais evidente em considerações como:

\title{
"não posso fazer nada sozinho, por mais que eu faça alguma coisa pra ajudar só resolve se tiver ajuda de todos" (A13).
}

Acreditando na coresponsabilidade, os participantes A13, A10, A08, falaram que não podem sozinhos praticar alguma atitude que contribua para diminuir a poluição de recursos hídricos, discursaram no sentido de que o problema é coletivo e precisa da ajuda de todos para que consiga surtir efeito satisfatório.

Embora o entendimento dos alunos faça sentido e haja uma necessidade coletiva de uso racional dos recursos naturais. Jacobi (2003) [34] explica que:

\begin{abstract}
"A realidade atual exige uma reflexão cada vez menos linear, e isto se produz na inter-relação dos saberes e das práticas coletivas que criam identidades e valores comuns e ações solidárias diante da reapropriação da natureza, numa perspectiva que privilegia o diálogo entre saberes. A preocupação com o desenvolvimento sustentável representa a possibilidade de garantir mudanças sociopolíticas que não comprometam os sistemas ecológicos e sociais que sustentam as comunidades" [34, p.191].
\end{abstract}

Dois participantes A18, A04, falaram que não podem fazer nada, ou seja, não se comprometem com o problema, assim como os oito que não responderam, e isso reforça, além das dificuldades de assumir responsabilidade social, indiferença ao problema abordado, evidenciando que um ensino descontextualizado e sem dialogo pode contribuir numa postura acrítica.

A sociedade indiferente, cheia de problemas que emergem com a globalização, uso irracional da tecnologia, a individualização, o subemprego entre outros, necessita de ações que valorizem o indivíduo como um ser que possa realmente fazer a diferença em todos os contextos, assim, a 
escola pode ajudar, trabalhando com temáticas socioambientais, que promovam a reflexão e o fazer [32, 34].

Os alunos A02, A01, A16, A17, A20, A09 e A197, falaram sobre a importância em usar menos sabões e detergentes, alguns falaram sobre trocar os detergentes agressivos por biodegradáveis, mostrando-se mais sensíveis aos problemas ambientais.

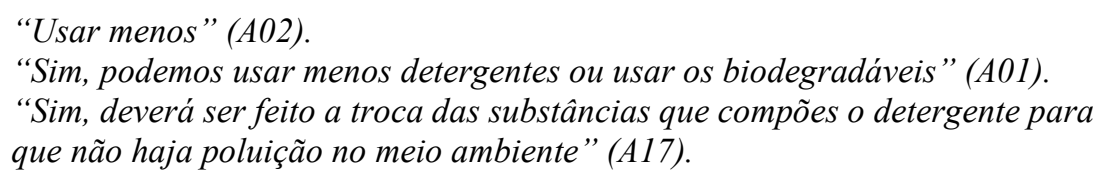

As responsabilidades dos cidadãos brasileiros quanto à gestão dos recursos hídricos estão previstas na constituição federal e quando se trata de legislação podemos dizer que o Brasil possui instrumentos legais que garante um dos melhores sistemas de gerenciamento de recursos hídricos do mundo, porém na prática as leis ainda não são cumpridas como deveriam. Assim, "como o cidadão não enxerga um posicionamento por parte das instituições, ele prefere acreditar naquilo que lhe agrada e não faz sua parte" [32].

Oito alunos A03, A05, A06, A07, A11, A12, A14 e A15 não opinaram, possivelmente por acreditar que o questionamento era apenas para reflexão.

O conhecimento cotidiano é decorrente de experiências sociais, que os indivíduos adquirem por meio de vivencias, hábitos e culturas ao qual pertencem, e isto acaba influenciando nas construções científicas do indivíduo, cabe ao ensino preparar esse estudante para utilizá-las dependendo do contexto com criticidade e responsabilidade.

\section{CONCLUSÃO}

Evidenciaram-se dificuldades dos estudantes em utilizar os três níveis de representação do conhecimento químico para argumentar e explicar os fenômenos dos experimentos, com tendência em utilizar apenas um dos níveis, geralmente o macroscópico, o que confirma que a abstração é um entrave a aprendizagem que precisa ser superada para melhor a aprendizagem da Química.

A aplicação dos conceitos químicos nas interpretações foi superficial, confirmando a necessidade de desenvolvimento de atividades, que integrem os saberes cotidianos e científicos, e facilitem a aprendizagem dos conceitos. Mesmo não se apropriando do conceito de solubilidade, houve uma evolução argumentativa e o uso de outros termos químicos nas explicações como densidade e mistura heterogênea, uma tentativa real de mobilização dos conhecimentos por parte dos alunos.

Mesmo utilizando uma temática de relevância para a vida desses estudantes e seus familiares, apenas $40 \%$ mostraram-se ao final preocupados com poluição dos recursos hídricos, com o restante entendendo que não podem fazer nada ou atribuindo responsabilidades a outros. Isso mostra que temáticas cotidianas precisam ser vivenciadas junto ao ensino conceitual para de fato promover uma postura mais crítica.

\section{AGRADECIMENTOS}

Agradecemos a Secretaria de Educação do Estado do Amazonas (SEDUC-AM) e Programa de Pós-Graduação em Ensino de Ciências e Matemática (PPGECIM-UFAM).

\section{REFERÊNCIAS BIBLIOGRÁFICAS}

1. Santos AO, Silva RP, Andrade D, Lima JPM. Dificuldades e Motivações de Aprendizagem em Química de Alunos do Ensino Médio Investigadas em Ações do (PIBID/UFS/Química). Sci Plena. 2013;9(7):077204-1.

2. Souza KAFD, Cardoso AA. Aspectos macro e microscópicos do conceito de equilíbrio químico e de sua abordagem em sala de aula. Quím Nova Escola. 2008;27:51-56. 
3. Zanotto RL, Silveira RMCF, Sauer E. Ensino de conceitos químicos em um enfoque CTS a partir de saberes populares. Ciênc Educ. 2016;22(3):727-740, doi: 10.1590/1516-731320160030011.

4. Neto MBS, Almeida SN, Feitosa, RA. Uso de Objetos de Aprendizagem para Abstração no Ensino de Química: Estado da Arte. Caminhos Ed Matem Rev. 2018;8(2):128-140.

5. Wharta EJ, Rezende DB. As Representações no Ensino de Química na Perspectiva da Semiótica Peirceana. Chem Educ Point View. 2017;1(1):181-202.

6. Borges AT. Novos Rumos para o Laboratório Escolar de Ciências. Cad Bras Ensino Física. 2002;19(3):291-313.

7. Melo MS, Silva RR. Os Três Níveis do Conhecimento Químico: Dificuldades dos Alunos na Transição entre o Macro, o Submicro e o Representacional. Rev Exitus. 2019;9(5):301-330, doi: 10.24065/22379460.2019v9n5ID1109.

8. Ferreira LH, Hartwig DR, Oliveira RC. Ensino Experimental de Química: uma Abordagem Investigativa Contextualizada. Quím Nova Escola. 2010;32(2):101-106.

9. Gibin GB, Lima SAM. Concepções dos licenciados do PIBID de Química/UNESP de Presidente Prudente sobre o papel pedagógico da experimentação. Sci Plena. 2015;11(6):067206-1.

10. Giordan M. O papel da experimentação no ensino de ciências. Quím Nova Escola. 1999;10:43-49.

11. Araújo MST, Abib MLVS. Atividades Experimentais no Ensino de Física: Diferentes Enfoques, Diferentes Finalidades. Rev Bras Ensino Física. 2003;25(2):176-194.

12. Oliveira JRS. Contribuições e Abordagens das Atividades Experimentais no Ensino de Ciências: Reunindo Elementos para a Prática Docente. Acta Scientiae. 2010;12(1):139-153.

13. Menezes JMS, Farias SA. O Desenvolvimento de Argumentação e Mobilização de Conceitos Químicos por meio da Atividade Experimental Investigativa. Rev Virtual Quím. 2020;12(1):223-233. doi:10.21577/1984-6835.20200017.

14. Oliveira SR, Gouveia VP, Quadros AL. Uma Reflexão sobre Aprendizagem Escolar e o Uso do Conceito de Solubilidade/Miscibilidade em Situações do Cotidiano: Concepções dos Estudantes. Quím Nova Escola. 2009;31(1):23-30.

15. Carmo MP, Marcondes MER. Abordando Soluções em Sala de Aula - uma Experiência de Ensino a partir das Ideias dos Alunos. Quím Nova Escola. 2008;28:37-41.

16. Santos WLP. Contextualização no Ensino de Ciências por meio de Temas CTS em uma Perspectiva Crítica. Ciên Ensino. 2007;1:1-12.

17. Wharta EJ, Rezende DB. Os Níveis de Representação no Ensino de Química e as Categorias da Semiótica de Peirce. Investig Ensino Ciên. 2011;16(2):275-290.

18. Ludke M, André MEDA Pesquisa em Educação: abordagens qualitativas. Rio de Janeiro; 2015. 128p.

19. Larocca P, Rosso AJ, Souza AP. A Formulação dos Objetivos de Pesquisa na Pós-Graduação em Educação: Uma Discussão Necessária. RBPG. 2005;2(3):118-133.

20. FOGAÇA, Jennifer Rocha Vargas. "Química dos sabões e detergentes"; Brasil Escola. Disponível em <http://brasilescola.uol.com.br/quimica/quimica-dos-saboesdetergentes.htm. Acessado em 10 de setembro de 2017.

21. Gurgel, JPL. Abordagem Ciência, Tecnologia e Sociedade (CTS) na Aprendizagem de Conceitos Químicos por Meio de Oficinas Temáticas [Dissertação]. Manaus (AM): Universidade Federal do Amazonas; 2018. 118p.

22. Gonçalves FP, Marques CA. Contribuições Pedagógicas e Epistemológicas em Textos de Experimentação no Ensino de Química. Investig Ensino Ciên. 2006;11(2):219-238.

23. Azzolin KAS. Concepções Prévias de Estudantes do Ensino Médio sobre Solubilidade e o Desenvolvimento de Atividades Experimentais como Ferramenta para a Melhoria do Ensino [Dissertação]. Santa Maria (RS): Universidade Federal de Santa Maria; 2012. 49 p.

24. Meneses FMG, Nunez IB. Erros e dificuldades de aprendizagem de estudantes do ensino médio na interpretação da reação química como um sistema complexo. Ciênc Educ. 2018;24(1):175-190, doi:10.1590/1516-731320180010012.

25. Gatti IC, Cerqueira PL, Silva BN, Coelho MMP, Afonso AF, Freitas-Reis I. Abordagem Temática no Ensino de Química: Solubilidade e Polaridade de Substâncias Orgânicas através das Vitaminas. Rev Ensino Pesquisa. 2015;13(01):166-187.

26. Schnetzler RP. A pesquisa em ensino de química no Brasil: conquistas e perspectivas. Quím Nova. 2002;25(1):14-24.

27. Marcondes MER, Carmo MP, Suart RC, Silva EL, Souza FL, Santos Jr JB, Akahoshi LH. Materiais Instrucionais numa Perspectiva CTSA: Uma Análise de Unidades Didáticas produzidas por Professores de Química em Formação Continuada. Investig Ensino Ciên. 2009;14(2):281-298. 
28. Leite BS. A Experimentação no Ensino de Química: Uma Análise das Abordagens nos Livros Didáticos. Educac Quím. 2018;29(3):61-78. doi: 10.22201/fq.18708404e.2018.3.63726.

29. Borges DKG. Lixo urbano como temática na promoção da cidadania e do ensino-aprendizagem de Química a partir do enfoque CTS [Dissertação]. Manaus (AM): Universidade Federal do Amazonas; 2017. $167 \mathrm{p}$.

30. Titoni M, Del Pino JC. Explorando Conceitos Químicos na Atividade Experimental Teor de Álcool na Gasolina. XIV Encontro Nacional de Ensino De Química (XIV ENEQ); 2008 Jul 21-24; Curitiba (PR). $10 \mathrm{p}$.

31. Silva LA, Martins CR, Andrade JB. Por que todos os Nitratos são solúveis?. Quím Nova. 2004;27(6):1016-1020.

32. Borges DKG, Farias SA, Souza, KS. Criticidade e Responsabilidade Socioambiental a partir da Temática Lixo Urbano. Rev Ensino Ciên Matem (REnCiMa). 2020;11(3):159-175, doi.org/10.26843/rencima.

33. Neto OGZ, Del Pino JC. Trabalhando a química dos sabões e detergentes. Universidade Federal do Rio Grande do Sul. Instituto de Química. Área de Educação Química. Disponível em http://www.quimica.seed.pr.gov.br/arquivos/File/AIQ_2011/saboes_ufrgs.pdf>. Acessado em 10 de setembro de 2017.

34. Jacobi PR. Educação ambiental, cidadania e sustentabilidade. Cad Pesq. 2003;118:189-205. 